\title{
Real-world study in severe eosinophilic asthma patients refractory to anti-IL5 biological agents treated with benralizumab in Spain (ORBE study)
}

Eva Martínez-Moragón ${ }^{*}$, Ismael García-Moguel ${ }^{2}$, Javier Nuevo ${ }^{3}$ and Gustavo Resler ${ }^{3}$ on behalf of ORBE study investigators

\begin{abstract}
Background: Benralizumab, a monoclonal antibody targeting the human interleukin-5 (IL-5) receptor (IL-5R), was used before marketing authorisation in Spain in a real world setting as part of an early-access programme (EAP) to treat patients with severe eosinophilic asthma with prior insufficient response or intolerance to anti-IL5 treatment (mepolizumab or reslizumab). The objective of this study is to describe the patient profile candidate for treatment and to assess benralizumab effectiveness.
\end{abstract}

Methods: This is an observational, retrospective, multicentre study in severe eosinophilic asthma patients refractory to other biological agents targeting the IL-5 pathway. Baseline characteristics included closest data, from the previous 12 months, to benralizumab treatment onset (index date). Patients were followed until the last treatment dosage while EAP was active (March to December 2018). Effectiveness was evaluated versus baseline, in patients who received at least three doses, with asthma control test (ACT), Mini Asthma Quality of Life Questionnaire (MiniAQLQ), annual severe exacerbation rate, oral corticosteroids treatment (OCS) and asthma-related healthcare resources utilization.

Results: Twenty-seven patients treated with benralizumab were included in the analysis. Effectiveness was assessed in 19 patients. Both questionnaires showed clinically meaningful differences, i.e. ACT score $\geq 3$ and MiniAQLQ score $\geq 0.5$, compared with baseline [mean (SD), 3.3 (6.8) and $1.2(1.9)$, respectively]. Patients treated with OCS decreased during follow-up from $88.9 \%(n=24 / 27)$ at baseline to $78.9 \%(n=15 / 19)$ and $31.6 \%(n=6 / 19)$ had an OCS dose reduction $\geq 50 \%$. The difference in annual severe exacerbation rate during follow-up showed a significant reduction vs. baseline (2.12 per patient-year, $95 \% \mathrm{Cl} 0.99-3.24, \mathrm{p}=0.002)$. The differences in annual rate of non-scheduled primary care and specialist visits during follow-up indicated a significant decrease [2.28 per patient-year $(95 \% \mathrm{Cl}$ $1.55-3.01 ; p<0.001)$ and 1.47 per patient-year (95\% Cl 0.65-2.30; $p=0.004)$, respectively], as well as the difference in annual rate of number of emergency department visits [1.18 per patient-year ( $95 \% \mathrm{Cl} 0.51-1.85 ; \mathrm{p}=0.007)$ ].

Conclusions: These results suggest that severe eosinophilic asthma patients receiving benralizumab, presented clinically meaningful improvement in asthma control and asthma-related QoL as well as OCS dose reduction. Results also

\footnotetext{
*Correspondence: evamartinezmoragon@gmail.com

1 Pneumology Service, University Hospital Doctor Peset, Valencia, Spain

Full list of author information is available at the end of the article
} original author(s) and the source, provide a link to the Creative Commons licence, and indicate if changes were made. The images or other third party material in this article are included in the article's Creative Commons licence, unless indicated otherwise in a credit line to the material. If material is not included in the article's Creative Commons licence and your intended use is not permitted by statutory regulation or exceeds the permitted use, you will need to obtain permission directly from the copyright holder. To view a copy of this licence, visit http://creativecommons.org/licenses/by/4.0/. The Creative Commons Public Domain Dedication waiver (http://creativeco mmons.org/publicdomain/zero/1.0/) applies to the data made available in this article, unless otherwise stated in a credit line to the data. 
aim to significant reductions in annual severe exacerbation rates, non-scheduled primary care and specialist visits, and emergency department visits rates.

Keywords: Asthma, Severe asthma, Eosinophilic asthma, Benralizumab, Biological treatment, Early access

programme

\section{Background}

Asthma is a chronic disease with a significant impact at personal, social and economic level with important implications in healthcare resources utilization involving those inherent in the disease treatment (emergency visits, hospitalisation, medical care, treatment costs, etc.) [1]. The burden of disease increases with increasing severity and lack of control $[1,2]$.

The prevalence of asthma in adults in Spain is approximately 5\% [3]. Between 6 and 10\% of all patients develop severe asthma and require long-term treatment with high dose inhaled corticosteroids (ICS) plus long-acting ß2-adrenergic agonists (LABA) and even, oral corticosteroids (OCS) to reach the target of asthma control [4]. Despite these treatments, most of these patients still have poor disease control, persistent limitation of airflow with frequent and severe exacerbations [5, 6].

According to the inflammatory cells present in blood, sputum or bronchial biopsy, there are different types of asthma phenotypes regarding the predominance of eosinophils, neutrophils, both cell types or none of them [7-9]. The current and future therapeutic approaches to asthma should include this stratification of patients according to these phenotyping criteria [10].

Several monoclonal antibodies are currently approved as add-on treatment for severe asthma patients in Spain. Omalizumab, mepolizumab, reslizumab, benralizumab and dupilumab have demonstrated efficacy in randomised clinical trials [11-16].

Benralizumab is a humanised monoclonal antibody (IgG1) which binds specifically to the alpha subunit of the receptor of the IL-5 present in eosinophils and basophils and results in apoptosis of these cells through antibody-dependent cell-mediated cytotoxicity (ADCC) by natural-killer (NK) and other cells [17]. Benralizumab has demonstrated efficacy in reducing severe exacerbations, increasing lung function, improving asthma-control and reducing, or even eliminating oral corticosteroids, regardless of the atopy status $[14,15,18-21]$.

Few real-life experience data are available to date because of the recent marketing approval of benralizumab. Many questions about responders' and nonresponders' characteristics, predictors of response, and residual disease after blocking the IL-5 pathway remain unanswered. Information on patients with partial response or no response to other anti-IL5 biologics and the effect of switching them to benralizumab is important to improve personalised treatment.

The Spanish Medicines Agency (AEMPS) authorised a programme in March 2018 for the prescription of benralizumab prior to commercialisation. This early-access programme (EAP) was based on the evidence of the persistent medical burden and unmet medical need of severe asthma patients and the potential efficacy differences between benralizumab and previously approved monoclonal antibodies in severe eosinophilic asthma.

The main objective of this study was to characterize the patient profile and to evaluate the effectiveness of benralizumab in real world setting as part of the EAP in Spain.

\section{Methods}

\section{Study design and study population}

This observational, retrospective, multicentre study involved 25 sites and included patients treated with at least one benralizumab dose during the EAP conducted in Spain between March 2018 and December 2018.

Written informed consent was obtained from all participants. The study was approved by the AEMPS. Additional approvals were obtained by several different ethics committees in compliance with local and regulatory guidelines.

Adults (18-year-olds or older) with severe eosinophilic asthma receiving high-dose ICS in combination with LABA (with or without another controller) unresponsive to other anti-IL5 biological agents available in Spain (mepolizumab or reslizumab), based on the physician's judgement were included. Benralizumab treatment initiation was also based on the physician's criteria according to the definition of severe eosinophilic asthma. Patients received the approved benralizumab dose of $30 \mathrm{mg}$ subcutaneously every 4 weeks for the first three doses and then every 8 weeks thereafter [22]. The presence or absence of a washout period between previous treatment and Benralizumab treatment initiation was at the investigator's discretion.

\section{Clinical, analytical, asthma-related resource consumption and lung function variables}

A database was compiled from patients' medical records. Baseline characteristics included closest data to 
benralizumab treatment onset (index date), and patients were followed-up until the last benralizumab treatment dosage while EAP was active (March to December 2018). Sociodemographic data (sex, age), basic blood test and clinical profile (age at diagnosis of asthma, atopy, asthmarelated and non-related comorbidities) were collected at index date.

Benralizumab effectiveness was measured comparing baseline versus follow-up only in those patients who received at least three doses of benralizumab, including asthma control (Asthma Control Test [ACT]) [23], lung function $\left(\mathrm{FEV}_{1}, \mathrm{FVC}\right)$, quality of life (MiniAQLQ), annual exacerbation rate, oral corticosteroids use, and asthmarelated healthcare resource use (non-scheduled primary care and specialist visits, as well as asthma-related ED visits). Annual exacerbation rate and asthma-related healthcare resources use at baseline were referred to the previous 12 months to index date.

Clinical outcomes data were collected. Severe asthma exacerbations (defined as hospital admission, OCS bursts or OCS dose increasing during $\geq 3$ days and emergency department asthma visits) and OCS use were collected for the year prior to and after benralizumab treatment initiation. The severity of exacerbations was defined according to the 2009 ATS/ERS consensus statement [24].

ACT is widely used in Spain [25] and available in electronic medical records for asthma control measure. The ACT has been validated in Spanish [26]. A test score under 20 indicates lack of control and a difference $\geq 3$ units is considered as clinically meaningful.

QoL was measured at baseline and after benralizumab treatment with the validated Spanish version of MiniAQLQ, self-administered by patients [27, 28]. The questionnaire evaluates four dimensions (symptoms, limitation of activities, emotional sphere and environmental stimulation) based on 15 questions rated 1 (always, worst) to 7 (never, better quality of life). A test score difference $\geq 0.5$ is considered as clinically meaningful.

Asthma-related healthcare resources use was also collected from medical records.

\section{Statistical analysis}

For continuous variables, descriptive statistics (n, mean, and standard deviation [SD]) are provided. For categorical variables, absolute frequency and valid percentages (i.e., excluding missing data) are provided. Patient demographic and clinical characteristics were summarised using descriptive statistics. Exacerbation rates in the year prior to treatment were expressed per patient-year and calculated before and after benralizumab treatment initiation as the number of episodes divided by time of exposure. Background controller treatment was also described and summarised using descriptive statistics (mean, SD, $\mathrm{n}$, and valid percentage). For the comparison of the same measurement at two different times, either paired T-test or Wilcoxon was used, depending on the sample distribution. Statistical significance was set at $p<0.05$. The analysis was performed using the IBM SPSS Statistics software, Version 22.0 (IBM Corp. Armonk, NY).

\section{Results \\ Clinical, functional, and laboratory data of patients at baseline}

Clinical, functional, and laboratory characteristics of the study population at baseline are shown in Table 1 .

A total of 27 severe asthma patients were evaluated, $88.9 \%(n=24)$ had eosinophilic asthma and $11.1 \%(n=3)$ also had atopic features. Mean (SD) time since diagnosis was 19.2 (13.8) years. At baseline, mean (SD) blood eosinophil count was 371.9 (315.5) cells $/ \mu \mathrm{L}$ and $55.6 \%$ $(\mathrm{n}=15)$ had $\geq 300$ cells $/ \mu \mathrm{L}$; mean (SD) ACT score was 14 (6.1) with a total of 21 patients $(77.8 \%)$ with uncontrolled asthma (ACT score $<20$ ).

All patients were treated with high-dose ICS plus LABA and $24(88.9 \%)$ had been treated with OCS as maintenance treatment prior to benralizumab initiation. Oral prednisone (equivalent) mean (SD) dose was 20.3 (20.1) $\mathrm{mg} /$ day. All patients had insufficient response or were intolerant to prior treatment with anti-IL5 or antiIgE treatment: $24(88.9 \%)$ had been previously treated with mepolizumab, 3 (11.1\%) with reslizumab and 2 (7.4\%) even received omalizumab before the anti-IL5 treatments.

Most of the patients had $\geq 1$ asthma-related comorbidity $(74.1 \% ; \mathrm{n}=20)$ (Table 2$)$. The most frequent were allergic rhinitis (44.4\%), nasal polyps (40.7\%), gastroesophageal reflux disease (40.7\%), and chronic rhinosinusitis (37\%) (Table 2).

\section{Clinical variables assessed after benralizumab treatment initiation}

Of the 27 patients evaluated at baseline, $70.4 \%(n=19)$ received at least three doses of benralizumab in the EAP and were evaluated at follow-up. $11.1 \%(\mathrm{n}=3)$ received two doses and $18.5 \%(n=5)$ received a single dose. The mean (SD) time between the first and the last dosage in those patients was 5 (2.1) months. Of these 19 patients, 89.5\% $(n=17)$ continued treatment with benralizumab after the EAP had been completed and following the approval and marketing authorisation of benralizumab in Spain. In contrast, two patients $(10.5 \%)$ discontinued the treatment with benralizumab after the EAP, in one case 
Table 1 Baseline patient characteristics

\begin{tabular}{|c|c|}
\hline Parameter & $N=27$ \\
\hline Age (years), mean (SD) & $49.8(12.7)$ \\
\hline Women, n (\%) & $14(51.9)$ \\
\hline BMI, mean (SD) & $28.4(5.9)$ \\
\hline \multicolumn{2}{|l|}{ Smoking, n (\%) } \\
\hline Non-smoker & $19(70.4)$ \\
\hline Former smoker & $8(29.6)$ \\
\hline Age at diagnosis (years), mean (SD) ${ }^{a}$ & $30.2(12.2)$ \\
\hline Time since diagnosis (years), mean (SD) & $19.2(13.8)$ \\
\hline \multicolumn{2}{|l|}{ Asthma phenotype, n (\%) } \\
\hline Eosinophilic & $24(88.9)$ \\
\hline Eosinophilic and atopic & $3(11.1)$ \\
\hline \multicolumn{2}{|l|}{ Pre-BD FEV ${ }_{1}$, mean $(S D)^{b}$} \\
\hline $\mathrm{mL}$ & $1,813.3(480.8)$ \\
\hline$\%$ & $62.1(14.6)$ \\
\hline \multicolumn{2}{|l|}{ Post-BD FEV 1 , mean $(\mathrm{SD})^{\mathrm{b}}$} \\
\hline $\mathrm{mL}$ & $1,989.3(819.7)$ \\
\hline$\%$ & $65.7(20.5)$ \\
\hline \multicolumn{2}{|l|}{$\mathrm{ACT}^{\mathrm{C}}$} \\
\hline Mean (SD) & $14(6.1)$ \\
\hline Controlled asthma (ACT $\geq 20), n(\%)$ & $6(22.2)$ \\
\hline miniAQLQ, mean (SD) & $3.4(0.7)$ \\
\hline FeNO (ppb), Mean (SD) ${ }^{d}$ & $76.2(56.5)$ \\
\hline Blood eosinophil count (cells/ $/ \mathrm{L}$ ), mean (SD) ${ }^{\mathrm{a}}$ & $371.9(315.5)$ \\
\hline$<300$ cells/ $\mu \mathrm{L}, \mathrm{n}(\%)$ & $11(40.7)$ \\
\hline$\geq 300$ cells/ $\mu \mathrm{L}, \mathrm{n}(\%)$ & $15(55.6)$ \\
\hline Total lgE (IU/ml), mean (SD) ${ }^{b}$ & $593.1(1,054.5)$ \\
\hline \multicolumn{2}{|l|}{ Asthma-treatment in the previous year, $\mathrm{n}(\%)$} \\
\hline$I C S+L A B A$ & $27(100)$ \\
\hline OCS & $24(88.9)$ \\
\hline LAMA & $22(81.5)$ \\
\hline LTRA & $17(63)$ \\
\hline ICS & $8(29.6)$ \\
\hline Macrolides & $6(22.2)$ \\
\hline Theophylline & $1(3.7)$ \\
\hline LABA & $1(3.7)$ \\
\hline \multicolumn{2}{|l|}{ Biologic agent } \\
\hline Mepolizumab (anti-IL5) & $23(85.2)$ \\
\hline Reslizumab (anti-IL5) & $2(7.4)$ \\
\hline Omalizumab (anti-lgE) (first line)/Mepolizumab (second line) & $1(3.7)$ \\
\hline Omalizumab (first line)/Reslizumab (second line) & $1(3.7)$ \\
\hline Oral prednisone dose (mg/day), mean (SD) & $20.3(20.1)$ \\
\hline Inhaled budesonide (in combination) dose ( $\mu \mathrm{g} /$ day), Mean (SD) & $305(60.2)$ \\
\hline \multicolumn{2}{|l|}{ Duration of prior biologic therapy (days), mean (SD) } \\
\hline Duration of prior mepolizumab therapy ${ }^{a}$ & $250.8(167.6)$ \\
\hline Duration of prior reslizumab therapy & $150.7(58.4)$ \\
\hline Duration of prior omalizumab therapy & $77(107.5)$ \\
\hline Time since prior biologic therapy (days), mean (SD) ${ }^{a}$ & $121.4(110.7)$ \\
\hline
\end{tabular}

ACT Asthma Control Test, AQLQ Asthma Quality of Life Questionnaire, BD bronchodilator, BMI body mass index, FeNO fractional exhaled nitric oxide, FEV ${ }_{1}$ forced expiratory volume in $1 \mathrm{~s}$, ICS inhaled corticosteroids, IL-5 Interleukin 5, IU international units, LABA long acting $\beta 2$-agonists, LAMA long acting muscarinic antagonists, LTRA leukotriene receptor antagonists, $\mu \mathrm{L}$ microliter, $m L$ millilitre, OCS oral corticosteroids, $p p b$ parts per billion, SD standard deviation, SPT skin prick test

${ }^{a}$ Data unknown in 1 case $(3.7 \%)$ 
Table 1 (continued)

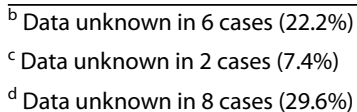

Table 2 Baseline patient comorbidities

\begin{tabular}{lc}
\hline Parameter & $\mathbf{N}=\mathbf{2 7}$ \\
\hline Asthma-related comorbidities, mean (SD) & $2(1.5)$ \\
Number of asthma-related comorbidities, $\mathrm{n}(\%)$ & \\
0 & $7(25.9)$ \\
1 & $1(3.7)$ \\
$\geq 2$ & $19(70.4)$ \\
Asthma-related comorbidities (frequency > 5\%), $\mathrm{n}(\%)$ & \\
Allergic rhinitis & $12(44.4)$ \\
Nasal polyps & $11(40.7)$ \\
Gastroesophageal reflux disease & $11(40.7)$ \\
Chronic rhinosinusitis & $10(37)$ \\
Allergic conjunctivitis & $5(18.5)$ \\
Atopic dermatitis & $4(14.8)$ \\
Other relevant comorbidities (frequency > 5\%), $\mathrm{n}(\%)$ & \\
Depression and anxiety & $10(37)$ \\
Obstructive sleep apnoea & $8(29.6)$ \\
Other diseases & $8(29.6)$ \\
Osteoporosis & $5(18.5)$ \\
Cardiovascular disease & $3(11.1)$ \\
Diabetes mellitus & $2(7.4)$ \\
\hline SD standard deviation &
\end{tabular}

because worsening of the symptoms, and, in the other case because occurrence of AEs. This information was not available in the case of the patients who received less than three doses of benralizumab in the EAP, according to the study protocol.

\section{Asthma control and quality of life}

Mean (SD) blood eosinophil counts decreased from 490 (353.9) at baseline to $0.8(2.8)$ cells/ $\mu$ l after treatment $(\mathrm{p}=0.002)$ (Table 3$)$.

According to data from the 19 patients that received at least the first three doses, pre-bronchodilator (preBD) and post-bronchodilator (post-BD) lung function showed no apparent difference after benralizumab treatment initiation compared with baseline, as showed in Table 3 and Fig. 1A-D. However, 9 (60\%) out of 15 patients had a clinically meaningful increase in $\mathrm{FEV}_{1}$ of $230 \mathrm{~mL}$.

Patients showed improvement in asthma control based on the ACT score after benralizumab treatment compared with baseline [14.8 (6.8) vs. 18.1 (6.3); $\mathrm{p}=0.079]$ (Table 3 and Fig. 1E). The point estimate difference between the last monitoring value and baseline was
3.3 (6.8), which is numerically larger than the minimal clinically important difference (MCID) (increase of $\geq 3$ units). Additionally, $60 \%(n=9)$ of the patients with ACT score recorded at baseline and after treatment initiation $(n=15)$ achieved a clinically significant response (ACT score difference $\geq 3$ ).

A significant reduction in the proportion of patients $(88.9 \%[n=24])$ receiving OCS at baseline vs. $78.9 \%$ $(n=15)$ after treatment initiation with benralizumab was observed and $31.6 \%(n=6)$ had an overall OCS dose reduction $\geq 50 \%$.

Regarding QoL, although not numerical difference $(\mathrm{p}=0.236)$, a MCID (score difference $\geq 0.5)$ in miniAQLQ of 1.2 (1.9) was observed vs. baseline (Table 3 and Fig. 1F).

\section{Exacerbations and asthma-related healthcare resources use}

As illustrated in Table 4, a reduction in the annualized exacerbation rate was observed between the year prior to treatment initiation and the time following benralizumab initiation [4.4 (2.9) vs. 1.9 (1.2) respectively]. The difference in the annual severe exacerbation rate was 2.12 (95\% CI 0.99-3.24) (i.e., 3.89 before treatment vs. 1.77 after treatment initiation, nominal $\mathrm{p}=0.002$ ) (Table 4). A total of 10 patients did not report exacerbations during follow-up after benralizumab treatment initiation $(11.1 \%$ of patients before treatment vs. $52.6 \%$ during followup). In contrast, $71.5 \%(n=22)$ of patients before treatment had $\geq 2$ exacerbations in the previous year vs. $21.1 \%$ $(n=4)$ after benralizumab treatment initiation.

Regarding asthma-related healthcare resources use, most of the patients had $\geq 1$ non-scheduled primary care and specialist visits in the year prior to benralizumab treatment (55.6\% and 59.3\%, respectively) (Table 5). In contrast, after benralizumab treatment initiation, the mean (SD) number of non-scheduled visits to primary care and specialists registered a reduction from 3.7 (3.9) to $1(0)$, and from $3.8(3.3)$ to $1.6(0.9)$, respectively. The observed differences during follow-up in the annual rate of non-scheduled visits to primary care and specialist were 2.28 (95\% CI 1.55-3.01; p < 0.001) and 1.47 (95\% CI 0.65-2.30; $\mathrm{p}=0.004)$, respectively. Also, the difference in annual rate of asthma-related ED visits was nominally statistically significant: 1.18 (95\% CI 0.51-1.85; $\mathrm{p}=0.007)$. 
Table 3 Asthma control and QoL at baseline and after benralizumab treatment initiation

\begin{tabular}{|c|c|c|}
\hline Variables & Baseline & $\begin{array}{l}\text { After } \\
\text { treatment } \\
\text { initiation }\end{array}$ \\
\hline \multicolumn{3}{|l|}{ Lung function } \\
\hline \multicolumn{3}{|l|}{ Pre-BD FEV ${ }_{1}(\mathrm{~mL}), \mathrm{N}=10$} \\
\hline Mean (SD) & $1,827(505.9)$ & $1,982(459.9)$ \\
\hline Difference, mean (SD) & $155(430.4)$ & \\
\hline$p$-value* & 0.284 & \\
\hline \multicolumn{3}{|l|}{ Pre-BD FEV ${ }_{1}(\%), N=10$} \\
\hline Mean (SD) & $63(18.8)$ & $68.9(20.7)$ \\
\hline Difference, mean (SD) & $5.8(17.3)$ & \\
\hline p-value* & 0.314 & \\
\hline \multicolumn{3}{|l|}{ Pre-BD FEV $1 / F V C(\%), N=10$} \\
\hline Mean (SD) & $59.8(9.9)$ & $56.2(24.2)$ \\
\hline Difference, mean (SD) & $-3.6(20)$ & \\
\hline p-value* & 0.441 & \\
\hline \multicolumn{3}{|l|}{ Post-BD FEV $(\mathrm{mL}), \mathrm{N}=9$} \\
\hline Mean (SD) & 2,093.3 (995.8) & $2,350(1,062.9)$ \\
\hline Difference, mean (SD) & $256.7(400.6)$ & \\
\hline p-value* & 0.091 & \\
\hline \multicolumn{3}{|l|}{ Post-BD FEV ${ }_{1}(\%), N=9$} \\
\hline Mean (SD) & $66.2(22.1)$ & $73.5(24.3)$ \\
\hline Difference, mean (SD) & $7.3(13.6)$ & \\
\hline$p$-value* & 0.147 & \\
\hline \multicolumn{3}{|l|}{ Post-BD FEV $1 / F V C(\%), N=9$} \\
\hline Mean (SD) & $65.2(11.8)$ & $67.4(12.5)$ \\
\hline Difference, mean (SD) & $2.2(5.8)$ & \\
\hline p-value* & 0.291 & \\
\hline \multicolumn{3}{|l|}{ Blood eosinophil count (cells/ $\mu \mathrm{L}$ ), $N=13$} \\
\hline Mean (SD) & $490(353.9)$ & $0.8(2.8)$ \\
\hline Difference, mean (SD) & $-489.2(354.4)$ & \\
\hline$p$-value* & 0.002 & \\
\hline OCS & $N=27$ & $N=19$ \\
\hline OCS-dependent, n (\%) & $24(88.9)$ & $15(78.9)$ \\
\hline OCS dose reduction $\geq 50 \%, \mathrm{n}(\%)$ & $6(31.6)^{\mathrm{a}}$ & \\
\hline \multicolumn{3}{|l|}{ Oral prednisone (mg/day), $\mathrm{N}=15$} \\
\hline Mean (SD) & $15.1(15.8)$ & $21.8(18.6)$ \\
\hline Difference, mean (SD) & $6.7(2.8)$ & \\
\hline p-value* & 0.144 & \\
\hline \multicolumn{3}{|l|}{ ACT, $N=15$} \\
\hline Mean (SD) & $14.8(6.8)$ & $18.1(6.3)$ \\
\hline Difference, mean (SD) & $3.3(6.8)$ & \\
\hline$p$-value* & 0.079 & \\
\hline Clinically meaningful difference $(\geq 3), n(\%)$ & $9(60)$ & \\
\hline \multicolumn{3}{|l|}{$\operatorname{mini} A Q L Q, N=5$} \\
\hline Mean (SD) & $3.6(0.8)$ & $4.7(1.5)$ \\
\hline Difference, mean (SD) & $1.2(1.9)$ & \\
\hline p-value* & 0.236 & \\
\hline Clinically meaningful difference $(\geq 0.5), n(\%)$ & $2(40)$ & \\
\hline
\end{tabular}

ACT AsthmaControl Test, AQLQ Asthma Quality of Life Questionnaire, $B D$ bronchodilator, $F E V_{1}$ forced expiratory volume in $1 \mathrm{~s}$, $F V C$ forced vitality capacity, $\mu L$ microliter, $\mathrm{mL}$ millilitre, OCS oral corticosteroids, $S D$ standard deviation

*Paired T-test 
Table 3 (continued)

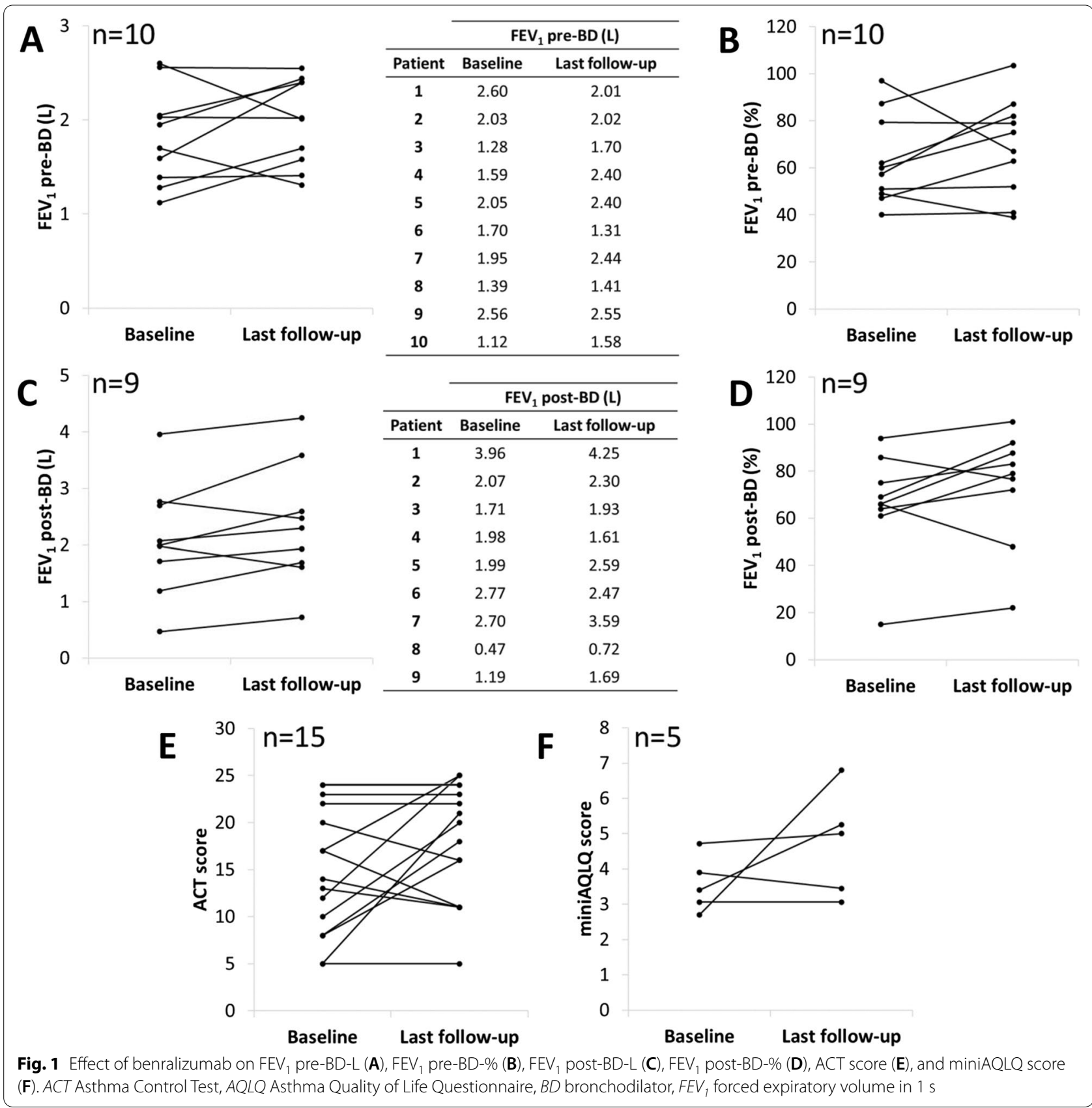

\section{Discussion}

This study suggests that in real world conditions, benralizumab reduces annual severe exacerbations rates, non-scheduled primary care and specialist visits, and emergency department visits, in patients mainly unresponsive to anti IL-5. Additionally, data suggest an important improvement in asthma control and asthmarelated QoL (ACT and miniAQLQ, respectively) as well as a reduction in the percentage of patients treated with OCS. Lung function improvement was clinically meaningful $\left(\mathrm{FEV}_{1}\right.$ change $=230 \mathrm{~mL}$; [29] $)$ in 9 out of 15 patients. 
Table 4 Severe exacerbations in the previous year and after treatment initiation with benralizumab

\begin{tabular}{|c|c|c|}
\hline Variables & Previous year $(\mathrm{N}=27)$ & $\begin{array}{l}\text { After treatment } \\
\text { initiation } \\
(\mathrm{N}=19)\end{array}$ \\
\hline Severe exacerbations, mean (SD) & $4.4(2.9)$ & $1.9(1.2)$ \\
\hline \multicolumn{3}{|l|}{ Annual rate of severe exacerbations } \\
\hline Rate per patient-year & 3.89 & 1.77 \\
\hline Difference & 2.12 & \\
\hline Cl 95\% & $0.99-3.24$ & \\
\hline p-value* & 0.002 & \\
\hline \multicolumn{3}{|l|}{ Number of exacerbations, n (\%) } \\
\hline 0 & $3(11.1)$ & $10(52.6)$ \\
\hline 1 & $2(7.4)$ & $5(26.3)$ \\
\hline 2 & $6(22.2)$ & $1(5.3)$ \\
\hline$\geq 3$ & $16(59.3)$ & $3(15.8)$ \\
\hline \multicolumn{3}{|l|}{ Category of exacerbation, n (\%) } \\
\hline OCS Bursts/dose increasing $\geq 3$ days & $24(88.9)$ & $8(42.1)$ \\
\hline Hospital admission & $5(18.5)$ & $2(10.5)$ \\
\hline ED visit & $9(33.3)$ & $5(26.3)$ \\
\hline \multicolumn{3}{|c|}{ Annual rate per category of exacerbation } \\
\hline \multicolumn{3}{|l|}{ OCS bursts/dose increasing $\geq 3$ days } \\
\hline Rate per patient-year & 3.93 & 1.46 \\
\hline Difference & 2.47 & \\
\hline C195\% & $1.40-3.54$ & \\
\hline$p$-value* & $<0.001$ & \\
\hline \multicolumn{3}{|l|}{ Hospital admission requirement } \\
\hline Rate per patient-year & 0.37 & 0.21 \\
\hline Difference & 0.16 & \\
\hline Cl95\% & $-0.21-0.53$ & \\
\hline$p$-value* & 0.707 & \\
\hline \multicolumn{3}{|l|}{ ED visit requirement } \\
\hline Rate per patient-year & 1.41 & 0.52 \\
\hline Difference & 0.89 & \\
\hline Cl95\% & $0.25-1.53$ & \\
\hline$p$-value* & 0.034 & \\
\hline
\end{tabular}

CI confidence interval, CS corticosteroids, ED emergency department, ICS inhaled corticosteroids, OCS oral corticosteroids, SD standard deviation

*Fisher's exact test

Benralizumab is safe and effective in patients with refractory eosinophilic asthma according to several clinical trials. However, even though real-life data may differ from data obtained from pivotal clinical trials due to their broader profile characteristics compared with those enrolled in clinical trials, our results are in line with pivotal benralizumab studies SIROCCO, CALIMA, and ZONDA [14, 15, 18].

Regarding the number of exacerbations in our study, the rate per patient-year dropped by $56.8 \%$ (from 4.4 at baseline to 1.9 after at least three benralizumab doses). In the SIROCCO and the CALIMA studies, reductions in exacerbations were $51 \%$ and $28 \%$ per year, respectively
$[14,15]$. This greater improvement compared to the pivotal studies is aligned with previous studies in real-life settings and could be related to broader severity degree and characteristics of patients analysed in usual clinical conditions studies [30, 31].

A real-life retrospective study evaluated data from 15 patients with difficult-to-treat, severe eosinophilic asthma treated with benralizumab for up to 6 months in Italy [31]. This study suggested that benralizumab is effective in improving ACT, AQLQ, and lung functional outcomes as well as in reducing the number of exacerbations. Similarly, a cross-sectional study evaluated 42 severe refractory eosinophilic asthma-patients treated 
Table 5 Asthma-related resources consumption

\begin{tabular}{|c|c|c|}
\hline Variables & Previous year $(\mathrm{N}=\mathbf{2 7})$ & $\begin{array}{l}\text { After treatment } \\
\text { initiation } \\
(\mathrm{N}=19)\end{array}$ \\
\hline \multicolumn{3}{|c|}{ Asthma-related non-scheduled visits } \\
\hline \multicolumn{3}{|l|}{ Primary care } \\
\hline Mean (SD) & $3.7(3.9)$ & $1(0)$ \\
\hline \multicolumn{3}{|l|}{ Number, n (\%) } \\
\hline 0 & $7(25.9)$ & $16(84.2)$ \\
\hline$\geq 1$ & $15(55.6)^{\mathrm{a}}$ & $2(10.5)^{b}$ \\
\hline Annual rate per patient-year & 2.50 & 0.22 \\
\hline Difference & 2.28 & \\
\hline Cl 95\% & $1.55-3.01$ & \\
\hline p-value* & $<0.001$ & \\
\hline \multicolumn{3}{|l|}{ Specialists } \\
\hline Mean (SD) & $3.8(3.3)$ & $1.6(0.9)$ \\
\hline \multicolumn{3}{|l|}{ Number, n (\%) } \\
\hline 0 & $10(37)$ & $14(73.7)$ \\
\hline$\geq 1$ & $16(59.3)^{c}$ & $5(26.3)$ \\
\hline Annual rate per patient-year & 2.31 & 0.83 \\
\hline Difference & 1.47 & \\
\hline Cl 95\% & $0.65-2.30$ & \\
\hline$p$-value* & 0.004 & \\
\hline \multicolumn{3}{|c|}{ Asthma-related hospital admissions } \\
\hline Mean (SD) & $2(1.4)$ & $1(0)$ \\
\hline \multicolumn{3}{|l|}{ Number, n (\%) } \\
\hline 0 & $22(81.5)$ & $17(89.5)$ \\
\hline$\geq 1$ & $5(18.5)$ & $2(10.5)$ \\
\hline Annual rate per patient-year & 0.37 & 0.21 \\
\hline Difference & 0.16 & \\
\hline Cl 95\% & -0.21 to 0.53 & \\
\hline$p$-value* & 0.707 & \\
\hline \multicolumn{3}{|l|}{ Asthma-related ED visits } \\
\hline Mean (SD) & $3.8(4.4)$ & $1(0)$ \\
\hline \multicolumn{3}{|l|}{ Number, n (\%) } \\
\hline 0 & $15(55.6)$ & $14(73.7)$ \\
\hline$\geq 1$ & $12(44.4)$ & $5(26.3)$ \\
\hline Annual rate per patient-year & 1.70 & 0.52 \\
\hline Difference & 1.18 & \\
\hline $\mathrm{Cl} 95 \%$ & $0.51-1.85$ & \\
\hline$p$-value* & 0.007 & \\
\hline
\end{tabular}

Cl confidence interval, ED emergency department, $S D$ standard deviation

*Fisher's exact test

${ }^{\text {a }}$ Data unknown in 5 cases (18.5\%)

${ }^{\text {b }}$ Data unknown in 1 case $(5.3 \%)$

${ }^{c}$ Data unknown in 1 case (3.7\%)

with benralizumab for at least 6 months in Spain [30]. This study not only confirmed the efficacy and safety of the treatment in real-life but also showed a rapid initial and persistent improvement during the first 6 months of treatment in lung function, control and quality of life. In these studies, less than half of the enrolled patients had been treated previously with anti-IL5 antibodies (mepolizumab or reslizumab). An additional observational study 
in Italy showed that the onset of effect of clinical effects of benralizumab on blood eosinophil count, symptom control, lung function and OCS intake (daily intake tapering from $15.58(8.30) \mathrm{mg} /$ day to $0 \mathrm{mg} /$ day) appear to be detectable as soon as 4 weeks after initiation of treatment. [32]. In this sense, responses may vary between the different anti-IL-5 biological agents, which may be due to differences in target, mode of administration, or dosing interval [33]. More specifically, real-life data showed enhanced responses to benralizumab in patients with severe eosinophilic asthma and chronic rhinosinusitis with nasal polyps (CRSwNP) [34].

Previously published pivotal lung function improvement results in patients with $\geq 300$ eosinophils $/ \mu \mathrm{L}$ (measured by $\mathrm{FEV}_{1}$ difference with placebo) were 0.159 $\mathrm{L}(\mathrm{p}=0.0006)$ and $0.116 \mathrm{~L}(\mathrm{p}=0.0102)$ in the SIROCCO and CALIMA studies, respectively [14, 15]. Real-world data results suggest that lung function continues to improve at 3 months and also at 6 months of treatment [30].

In real world conditions, anti-IL-5 (mepolizumab, reslizumab), and anti-IL-5R (benralizumab) biologic agents have shown that more than $80 \%$ of patients with severe eosinophilic asthma have a favourable long-term response to these treatments, although switches between biologics were frequent (34\% of patients switched to other anti-IL5 or anti-IL5R, and 7\% made 2 switches) $[33,35]$. Most frequent reported reasons for switching were persistent asthma or sinonasal symptoms, including exacerbations, whereas only a small percentage switched because of adverse events [33].

In this analysis, super response was observed in $14 \%$ of patients and only $11 \%$ of patients were defined as non-responders [33]. Our results showed a numerically increase in the magnitudes of lung function measurements, both in $\mathrm{FEV}_{1}$ and $\mathrm{FEV}_{1} / \mathrm{FVC}$, whereas no apparent difference after benralizumab treatment initiation compared with baseline. Thus, considering the observed improvement in other outcomes of the study, these changes in the lung function magnitudes that we observed in our results, after at least the first three doses of benralizumab, may continue to improve. Our analysis also showed an improving trend in ACT and miniAQLQ score differences between baseline and after at least the first three benralizumab doses, higher than what are considered as clinically meaningful differences $(\mathrm{ACT} \geq 3$ and miniAQLQ $\geq 0.5$ ). A recent study in real-life conditions observed that a single dose of benralizumab led to a rapid and remarkable improvement in symptom control and airflow limitation together with an immediate withdrawal of OCS therapy [32]. This quick therapeutic action probably results from the effective depletion of eosinophils induced via IL-5R blockade and ADCC-mediated apoptosis of these cells [32]. All these data together indicate that, although the improvement trend can be enhanced in the long term, asthma-control improvement is rapidly observed after at least the first three doses of benralizumab.

Patients mainly unresponsive to previous anti-IL-5 treatment and requiring stable treatment with high-dose ICS and at least one LABA were enrolled in the ORBE study. Study results suggest that benralizumab treatment could improve asthma control in patients who have previously failed to respond or discontinued treatment with mepolizumab or reslizumab. Even with its limitations, the information in this study is pertinent as it suggests that difficult to treat patients who have received, anti-IgE or anti-IL5 biologic treatment may derive benefit from being switched to bernalizumab. Recent studies and posthoc analyses have shown that patients whose asthma did not respond to omalizumab can improve with a biologic treatment targeting the IL-5 pathway in terms of asthma control, exacerbations, and OCS reduction [30, 36-38]. Thus, benralizumab could be an effective option in severe eosinophilic asthma and could be considered as a first option before starting another biologic treatment targeting the IL-5 pathway.

The study has several limitations. It is a relatively small sample size with a short follow up period as the number of enrolled patients and length of follow-up were dictated by EAP limitations. Some additional limitations are inherent to the retrospective design such as proclivity to recall bias or misclassification bias, presence of confounding factors (other risk factors may be present that were not measured), and the inability to fully determine causation, association and temporal relationships. The absence of an active comparator arm or placebo arm makes drawing formal conclusions difficult. Due to the nature of this retrospective analysis, there is no available data of clinical information of the baseline data before initiation of any biologic treatment.

On the other hand, one of the main strengths of the ORBE study is that this is a real-life setting study describing the very first usual clinical practice with benralizumab. Besides, patients included in the study comprised a broader and more heterogeneous population than the population included in the pivotal studies. Additionally, all patients had been previously treated with other biologics. The ORBE study highlights the importance of expanded-access programmes, which allow patients with unmet clinical needs to benefit from treatment based on available evidence before health authority approval and commercial distribution. 


\section{Conclusions}

This study in a real-life setting study suggests that benralizumab is effective in in the treatment of patients with severe eosinophilic asthma and an incomplete or absent response to treatment with other biologic agents, including anti-IL5 (mepolizumab or reslizumab). Results also suggests an improvement in clinical outcomes after few doses of benralizumab indicating a rapid onset of effect, which is likely to improve over time. Benralizumab was well tolerated with a safety profile which was commensurate with previous studies.

\begin{abstract}
Acknowledgements
The authors wish to acknowledge the editorial assistance of Alicia SubtilRodríguez (Dynamic Science S.L.U.).

The authors also wish to acknowledge all the ORBE study investigators: Ignacio Antépara (Hospital Universitario Basurto); Ebymar Arismendi-Núñez (Hospital Clinic i Provincial, Barcelona); Francisco Casas-Maldonado (Hospital Universitario San Cecilio, Granada); Ignacio Dávila-González (Complejo Asistencial Universitario de Salamanca); Ismael García-Moguel (Hospital Universitario 12 de Octubre, Madrid); Jose Luis Velasco-Garrido (Hospital Universitario Virgen de la Victoria, Málaga); Rocío Díaz-Campos (Hospital Universitario 12 de Octubre, Madrid); Carmen Díaz-Donado (Hospital Universitario Central de Asturias, Oviedo); Beatriz Gálvez (Hospital Universitario del Vinalopó); Jose Luis Izquierdo (Hospital Universitario de Guadalajara); Antolín López-Viña (Hospital Universitario Puerta de Hierro, Madrid); Eva Martínez-Moragón (Hospital Universitario Doctor Peset, Valencia); Cristina Navarro-Soriano (Hospital General de Requena); Marta Palop-Cervera (Hospital de Sagunto);Luis Pérez de Llano (Hospital Universitario Lucus Augusti, Lugo); Vicente Plaza (Hospital de la Santa Creu i Sant Pau, Barcelona); Miguel Ángel Racionero-Casero (Hospital Universitario de Fuenlabrada, Madrid); Manuel Rial-Prado (Complejo Hospitalario Universitario de A Coruña); Marina Carmen Rodríguez-Hernández (Hospital General de la Santísima Trinidad, Salamanca); Maria Jesús Rodríguez-Nieto (Fundación Jiménez Díaz, Madrid) and Miguel Zabaleta (Hospital Universitario Marqués de Valdecilla, Santander).
\end{abstract}

\section{Authors' contributions}

EMM, IGM, JN and GR drafted the study, took active part in the acquisition of data, analysis and interpretation of the study data. EMM, IGM, JN and GR drafted and revised the manuscript. EMM, IGM, JN and GR provided critical review and approved the final version. All authors read and approved the final manuscript.

\section{Funding}

This study has been sponsored by AstraZeneca Farmacéutica Spain. AstraZeneca Farmacéutica Spain was involved in the study design, collection, analysis, and interpretation of the data, in the writing of the report, and in the decision to submit the article for publication.

\section{Availability of data and materials}

All data in the manuscript is available through the responsible corresponding author.

\section{Declarations}

\section{Ethics approval and consent to participate}

This study was approved by the AEMPS and by the ethics committee of the Hospital Universitario 12 de Octubre of Madrid. Written informed consent was obtained from all participants.

\section{Consent for publication}

Not applicable.

\section{Competing interests}

EM-M received honoraria for lectures, presentations, speaker bureaus, manuscript writing, or educational events from ALK, AstraZeneca, GlaxoSmithKline, Novartis, Pfizer, Sanofi, and TEVA; has received equipment, materials, or other services from GlaxoSmithKline; and has served as a paid expert and was a member of advisory boards for AstraZeneca, Bial, GlaxoSmithKline, Novartis, Sanofi, and TEVA. IG-M received honoraria for lectures, presentations, speaker bureaus, manuscript writing, or educational events from Allergy Therapeutics, AstraZeneca, Chiesi, GlaxoSmithKline, Leti, Orionpharma, Sanofi, and Stallergenes; has received equipment, materials, or other services from GlaxoSmithKline; and has served as a paid expert and was a member of advisory boards for AstraZeneca, GlaxoSmithKline, and Sanofi. JN and GR are employees of AstraZeneca.

\section{Author details}

${ }^{1}$ Pneumology Service, University Hospital Doctor Peset, Valencia, Spain. ${ }^{2}$ Severe Asthma Unit, Allergy Department, Hospital Universitario, 12 de Octubre, Madrid, Spain. ${ }^{3}$ AstraZeneca Farmacéutica Spain S.A., Madrid, Spain.

Received: 28 June 2021 Accepted: 8 December 2021

Published online: 18 December 2021

\section{References}

1. Israel E, Reddel HK. Severe and difficult-to-treat asthma in adults. N Engl J Med. 2017;377(10):965-76.

2. Melero Moreno C, Quirce S, Huerta A, Uria E, Cuesta M. Economic impact of severe asthma in Spain: multicentre observational longitudinal study. J Asthma. 2019;56(8):861-71.

3. Guía Española para el Manejo del Asma (GEMA 5.0). https://www.separ. es/node/1812.

4. Álvarez-Gutiérrez FJ, Blanco-Aparicio M, Plaza V, Cisneros C, García-Rivero JL, Padilla A, Pérez-de Llano L, Perpiñá M, Soto-Campos G. Documento de consenso de asma grave en adultos. Actualización 2020. Open Respir Arch. 2020;2(3):158-74.

5. Pavord ID, Mathieson N, Scowcroft A, Pedersini R, Isherwood G, Price D. The impact of poor asthma control among asthma patients treated with inhaled corticosteroids plus long-acting beta2-agonists in the United Kingdom: a cross-sectional analysis. NPJ Prim Care Respir Med. 2017;27(1):17.

6. Demoly P, Paggiaro P, Plaza V, Bolge SC, Kannan H, Sohier B, Adamek L. Prevalence of asthma control among adults in France, Germany, Italy, Spain and the UK. Eur Respir Rev. 2009;18(112):105-12.

7. Ray A, Raundhal M, Oriss TB, Ray P, Wenzel SE. Current concepts of severe asthma. J Clin Investig. 2016:126(7):2394-403.

8. Bartemes KR, Kephart GM, Fox SJ, Kita H. Enhanced innate type 2 immune response in peripheral blood from patients with asthma. J Allergy Clin Immunol. 2014;134(3):671-678.e74.

9. Pelaia G, Vatrella A, Busceti MT, Gallelli L, Calabrese C, Terracciano R, Maselli R. Cellular mechanisms underlying eosinophilic and neutrophilic airway inflammation in asthma. Mediat Inflamm. 2015;2015(10):879783.

10. Fajt ML, Wenzel SE. Asthma phenotypes and the use of biologic medications in asthma and allergic disease: the next steps toward personalized care. J Allergy Clin Immunol. 2015;135(2):299-310 (quiz 311).

11. Humbert M, Beasley R, Ayres J, Slavin R, Hébert J, Bousquet J, Beeh KM, Ramos S, Canonica GW, Hedgecock S, et al. Benefits of omalizumab as add-on therapy in patients with severe persistent asthma who are inadequately controlled despite best available therapy (GINA 2002 step 4 treatment): INNOVATE. Allergy. 2005;60(3):309-16.

12. Ortega HG, Liu MC, Pavord ID, Brusselle GG, FitzGerald JM, Chetta A, Humbert M, Katz LE, Keene ON, Yancey SW, et al. Mepolizumab treatment in patients with severe eosinophilic asthma. N Engl J Med. 2014;371(13):1198-207.

13. Castro M, Zangrilli J, Wechsler ME, Bateman ED, Brusselle GG, Bardin P, Murphy K, Maspero JF, O'Brien C, Korn S. Reslizumab for inadequately controlled asthma with elevated blood eosinophil counts: results from two multicentre, parallel, double-blind, randomised, placebo-controlled, phase 3 trials. Lancet Respir Med. 2015;3(5):355-66.

14. Bleecker ER, FitzGerald JM, Chanez P, Papi A, Weinstein SF, Barker P, Sproule S, Gilmartin G, Aurivillius M, Werkstrom V, et al. Efficacy and safety 
of benralizumab for patients with severe asthma uncontrolled with high-dosage inhaled corticosteroids and long-acting beta2-agonists (SIROCCO): a randomised, multicentre, placebo-controlled phase 3 trial. Lancet. 2016;388(10056):2115-27.

15. FitzGerald JM, Bleecker ER, Nair P, Korn S, Ohta K, Lommatzsch M, Ferguson GT, Busse WW, Barker P, Sproule S, et al. Benralizumab, an antiinterleukin-5 receptor alpha monoclonal antibody, as add-on treatment for patients with severe, uncontrolled, eosinophilic asthma (CALIMA): a randomised, double-blind, placebo-controlled phase 3 trial. Lancet. 2016;388(10056):2128-41.

16. Castro M, Corren J, Pavord ID, Maspero J, Wenzel S, Rabe KF, Busse WW, Ford L, Sher L, FitzGerald JM, et al. Dupilumab efficacy and safety in moderate-to-severe uncontrolled asthma. N Engl J Med. 2018;378(26):2486-96.

17. Kolbeck R, Kozhich A, Koike M, Peng L, Andersson CK, Damschroder MM, Reed JL, Woods R, Dall'acqua WW, Stephens GL, et al. MEDI-563, a humanized anti-IL-5 receptor alpha mAb with enhanced antibodydependent cell-mediated cytotoxicity function. J Allergy Clin Immunol. 2010;125(6):1344-1353.e1342.

18. Nair P, Wenzel S, Rabe KF, Bourdin A, Lugogo NL, Kuna P, Barker P, Sproule S, Ponnarambil S, Goldman M, et al. Oral glucocorticoid-sparing effect of benralizumab in severe asthma. N Engl J Med. 2017;376(25):2448-58.

19. Chipps BE, Newbold P, Hirsch I, Trudo F, Goldman M. Benralizumab efficacy by atopy status and serum immunoglobulin E for patients with severe, uncontrolled asthma. Ann Allergy Asthma Immunol. 2018;120(5):504-511.e504

20. Menzies-Gow A, Gurnell M, Heaney LG, Corren J, Bel EH, Maspero J, Harrison T, Jackson DJ, Price D, Lugogo N, et al. Oral corticosteroid elimination via a personalised reduction algorithm in adults with severe, eosinophilic asthma treated with benralizumab (PONENTE): a multicentre, open-label, single-arm study. Lancet Respir Med. 2021. https://doi.org/10.1016/ S2213-2600(21)00352-0.

21. Pelaia C, Crimi C, Benfante A, Caiaffa MF, Calabrese C, Carpagnano GE, Ciotta D, D'Amato M, Macchia L, Nolasco S, et al. Therapeutic effects of benralizumab assessed in patients with severe eosinophilic asthma: real-life evaluation correlated with allergic and non-allergic phenotype expression. J Asthma Allergy. 2021;14:163-73.

22. Fasenra $30 \mathrm{mg}$ solution for injection in pre-filled syringe (Summary of Product Characteristics (SPC)). In.

23. Crimi C, Campisi R, Noto A, Genco S, Cacopardo G, Nolasco S, Crimi N. Comparability of asthma control test scores between self and physicianadministered test. Respir Med. 2020;170:106015.

24. Reddel HK, Taylor DR, Bateman ED, Boulet LP, Boushey HA, Busse WW, Casale TB, Chanez P, Enright PL, Gibson PG, et al. An official American Thoracic Society/European Respiratory Society statement: asthma control and exacerbations: standardizing endpoints for clinical asthma trials and clinical practice. Am J Respir Crit Care Med. 2009;180(1):59-99.

25. Nathan RA, Sorkness CA, Kosinski M, Schatz M, Li JT, Marcus P, Murray $\mathrm{J}$, Pendergraft TB. Development of the asthma control test: a survey for assessing asthma control. J Allergy Clin Immunol. 2004;113(1):59-65.

26. Vega JM, Badia X, Badiola C, Lopez-Vina A, Olaguibel JM, Picado C, Sastre J, Dal-Re R, Covalair Investigator G. Validation of the Spanish version of the Asthma Control Test (ACT). J Asthma. 2007:44(10):867-72.

27. Juniper EF, Guyatt GH, Cox FM, Ferrie PJ, King DR. Development and validation of the Mini Asthma Quality of Life Questionnaire. Eur Respir J. 1999;14(1):32-8.

28. Sanjuas C, Alonso J, Ferrer M, Curull V, Broquetas JM, Anto JM. Adaptation of the Asthma Quality of Life Questionnaire to a second language preserves its critical properties: the Spanish version. J Clin Epidemiol. 2001;54(2):182-9.

29. Holguin F, Cardet JC, Chung KF, Diver S, Ferreira DS, Fitzpatrick A, Gaga M, Kellermeyer L, Khurana S, Knight S, et al. Management of severe asthma: a European Respiratory Society/American Thoracic Society guideline. Eur Respir J. 2020;55(1):00588-2019.

30. Padilla-Galo A, Levy-Abitbol R, Olveira C, Valencia Azcona B, Perez Morales M, Rivas-Ruiz F, Tortajada-Goitia B, Moya-Carmona I, Levy-Naon A. Reallife experience with benralizumab during 6 months. BMC Pulm Med. 2020;20(1):184.

31. Di Bona D, Minenna E, Albanesi M, Nettis E, Caiaffa MF, Macchia L. Benralizumab improves patient reported outcomes and functional parameters in difficult-to-treat patients with severe asthma: Data from a real-life cohort. Pulm Pharmacol Ther. 2020;64(101974):101974.

32. Pelaia C, Busceti MT, Vatrella A, Rago GF, Crimi C, Terracciano R, Pelaia G. Real-life rapidity of benralizumab effects in patients with severe allergic eosinophilic asthma: assessment of blood eosinophils, symptom control, lung function and oral corticosteroid intake after the first drug dose. Pulm Pharmacol Ther. 2019;58(101830):101830.

33. Eger K, Kroes JA, Ten Brinke A, Bel EH. Long-term therapy response to anti-IL-5 biologics in severe asthma - a real-life evaluation. J Allergy Clin Immunol Pract. 2021;9(3):1194-200.

34. Nolasco S, Crimi C, Pelaia C, Benfante A, Caiaffa MF, Calabrese C, Carpagnano GE, Ciotta D, D'Amato M, Macchia L, et al. Benralizumab effectiveness in severe eosinophilic asthma with and without chronic rhinosinusitis with nasal polyps: a real-world multicenter study. J Allergy Clin Immunol Pract. 2021. https://doi.org/10.1016/j.jaip.2021.08.004.

35. Crimi C, Campisi R, Cacopardo G, Intravaia R, Nolasco S, Porto M, Pelaia C, Crimi N. Real-life effectiveness of mepolizumab in patients with severe refractory eosinophilic asthma and multiple comorbidities. World Allergy Organ J. 2020;13(9):100462.

36. Perez de Llano LA, Cosio BG, Domingo C, Urrutia I, Bobolea I, Valero A, Entrenas Costa LM, Quirce S, Barranco P, Marina Malanda N, et al. Efficacy and safety of reslizumab in patients with severe asthma with inadequate response to omalizumab: a multicenter, open-label pilot study. J Allergy Clin Immunol Pract. 2019;7(7):2277-2283.e2272.

37. Chapman KR, Albers FC, Chipps B, Munoz X, Devouassoux G, Bergna M, Galkin D, Azmi J, Mouneimne D, Price RG, et al. The clinical benefit of mepolizumab replacing omalizumab in uncontrolled severe eosinophilic asthma. Allergy. 2019;74(9):1716-26.

38. Magnan A, Bourdin A, Prazma CM, Albers FC, Price RG, Yancey SW, Ortega $\mathrm{H}$. Treatment response with mepolizumab in severe eosinophilic asthma patients with previous omalizumab treatment. Allergy. 2016;71(9):1335-44.

\section{Publisher's Note}

Springer Nature remains neutral with regard to jurisdictional claims in published maps and institutional affiliations.

\footnotetext{
Ready to submit your research? Choose BMC and benefit from:

- fast, convenient online submission

- thorough peer review by experienced researchers in your field

- rapid publication on acceptance

- support for research data, including large and complex data types

- gold Open Access which fosters wider collaboration and increased citations

- maximum visibility for your research: over 100M website views per year
}

At BMC, research is always in progress.

Learn more biomedcentral.com/submissions 